\title{
SARS-CoV-2: The Prominent Role of Non-structural Proteins (NSPS) in COVID-19
}

\author{
Uma Sankar Gorla*, GSN Koteswara Rao \\ College of Pharmacy, Koneru Lakshmaiah Education Foundation, Vaddeswaram, Andhra Pradesh, INDIA.
}

\begin{abstract}
COVID-19, an infectious contagious viral (SARS-CoV-2) disease, associated with morbidity and mortality from respiratory pandemic worldwide. Currently, COVID-19 has no targeted treatment strategies and has been declared by WHO as a global health emergency. SARS-CoV-2, an enveloped, positive-sense, betacoronavirus ( $\beta \mathrm{CoV}$ ) spreading rapidly due to its potential pre- and asymptomatic transmission (silent transmission). The viral replicase single-stranded genome encodes for two open reading frame genes (orf1a and orf1b), that are translated into two polyproteins, pp $1 \mathrm{a}$ and $\mathrm{pp} 1 \mathrm{~b}$. Viral proteases including papain-like protease (PL-PRO) and chymotrypsin-like protease (3CL-PRO) pre-processes and fragments the polyproteins into 16 non-structural proteins (Nsps) that are assembled into replicase-transcriptase complex and exhibit multiple enzymatic activity. To rationalize their evolutionary success and develop improved control strategies, understanding the main functions and interactions of non-structural proteins of SARS-CoV-2 will be essential. Based on the existing published literature, this review summarizes the knowledge on multiple pathologic functions of Nsps in COVID-19. This review is hoped to help the researchers to understand the significant role of nonstructural proteins in COVID-19 and provide a reference for future studies.
\end{abstract}

Key words: COVID-19, SARS-CoV-2, Non-structural proteins, Open reading frames, Polyproteins, Phylogenetic analysis.

Key Message: The putative non-structural proteinsof SARS-CoV-2 assembled into replicase-transcriptase complex and exhibit multiple enzymatic activity and play a vital role in COVID-19.

\section{INTRODUCTION}

Coronavirus disease 2019 (COVID-19), a pandemic infectious respiratory disease caused by an enveloped, positive-sense, single-stranded RNA novel coronavirus named as SARS-CoV-2. ${ }^{1,2}$ As of 23 July 2020 , WHO reported 1,50,12,731 cases globally in 216 countries including 6,19,150 deaths for the Corona outbreak 2019 and it has been declared as a global health emergency (https: / / www.who.int/emergencies/ diseases/novel-coronavirus-2019). The virus has locked down the millions and the catastrophes are threatening the global economy. ${ }^{3}$ COVID-19 is a highly contagious disease associated with morbidity and mortality due to its potential pre- and asymptomatic transmission. ${ }^{4}$
SARS-CoV-2 belongs to the order Nidovirales, the family Coronaviridae, the genus Betacoronavirus and the species Severe acute respiratory syndrome-related coronavirus. ${ }^{5}$ SARS-CoV-2, which is responsible for the COVID-19 pandemic, is spreading rapidly all over the globe due to the transmission from human-to-human. ${ }^{6}$ The SARS-CoV-2 reproductive number is 2.68 with an incubation period of 6.4 days (range 2.1 to 11.1 days) and the time of onset of symptoms is between 1 and 14 days, usually 5 days. ${ }^{7}$ Studies have found that majority of COVID-19 transmission is due to silent spreaders that do not show symptoms. ${ }^{8}$ The silent transmission of SARS-CoV-2 infection is due to virus
Submission Date: 10-04-2020; Revision Date: 22-06-2020 Accepted Date: 13-08-2020

DOI: 10.5530/ijper.54.3s.136 Correspondence: Mr. Uma Sankar Gorla K L College of Pharmacy, Koneru Lakshmaiah Education Foundation, Vaddeswaram, Guntur-522 502, Andhra Pradesh, INDIA. Phone: +918500444400 E-mail: umasankargorla@ gmail.com

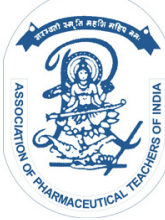

www.ijper.org 
shedding patterns in asymptomatic patients. ${ }^{9}$ Recent studies indicates that SARS-CoV-2 shedding may begin 2 to 3 days before the onset of first clinical signs and symptoms. ${ }^{10}$ Regarding the potential routes of SARS-CoV-2 transmission, respiratory route was the most predominant route in humans. However, recent evidences indicates that the SARS-CoV-2 may also be transmitted through the fecal-oral route, since the virus was found in endoscopic and stool specimens from COVID-19 patients. ${ }^{11}$ The ongoing epidemic originally identified as pneumonia of unknown etiology in a group of patients in Wuhan, China. ${ }^{12}$ The Chinese Centre for Disease Control and Prevention (CDC, China) subsequently categorized the clinical manifestations of COVID-19 based on the severity with a wide range of clinical symptoms ranging from asymptomatic patients to septic shock and multiorgan dysfunction. ${ }^{13}$ The most frequently reported symptoms of COVID-19 includes fever, dry cough and fatigue. ${ }^{14}$ In addition to pulmonary symptoms, $2 \%$ to $10 \%$ of COVID-19 patients reported GIT manifestations such as nausea, vomiting, diarrhoea and abdominal pain. ${ }^{15}$ Extra pulmonary and systemic manifestations such as cardiac arrhythmias, cardiac failure, deep vein thrombosis, renal tissue damage, liver damage, seizures, Guillain-Barre syndrome and confusion are caused by a direct attack of SARS-CoV-2 on cardiac muscles, kidneys, blood vessels, liver and central nervous system with ACE2 receptors. ${ }^{16}$ Furthermore, SARS-CoV-2 targets male reproductive system due to high expression of ACE2 and has been detected in semen. ${ }^{17}$ The complications include spermatogenic failure, autoimmune orchitis, hypogonadism, germ cell destruction, testicular dysfunction and infertility. ${ }^{18}$

Despite these recent discoveries, the current review aimed to summarize the existing literature on multiple pathologic functions of non-structural proteins in SARS-CoV-2 replication and virulence.

\section{SARS-CoV-2 genomic organization}

Phylogenetic studies of the SARS-CoV-2 have shown a nucleotide correlation of $96 \%$ with Bat-SL-RaTG13, $88 \%$ with Bat-SL-Cov-ZC45 and Bat-SL-CoV-ZXC21, $79.6 \%$ with SARS-CoV and $50 \%$ with MERS-CoV. ${ }^{19}$ The analysis revealed that the single-stranded RNA genome (30kb) of SARS-CoV-2 was 29,891 nucleotides in size (9860 amino acids) encoding up to 14 open reading frames (orfs). ${ }^{20,21}$ The 5 -and 3 '- untranslated regions of SARS-CoV-2 are identical to those of $\beta \mathrm{CoVs}$ in nucleotide sequence $(\geq 83.6 \%)$. In genetic configuration, the genome is organized as 5 -replicasestructural proteins along with accessory factors- $3^{\prime}$. The 5 replicase genome encodes two open reading frame genes (orf1a and orf1b), that are translated into two polyproteins, pp1a and pp1b. ${ }^{22}$ These polyproteins were pre-processed and fragmented by viral proteases into 16 non-structural proteins (NSPS), which are assembled into replicase-transcriptase complex and exhibit multiple enzymatic activity (Table 1). ${ }^{23}$ The putative non-structural proteins in the replicasetranscriptase complex includes the papain-like protease (Nsp3, PL-PRO), the main protease (Nsp5, Main protease $\left(\mathrm{M}^{\mathrm{pro}}\right)$, chymotrypsin-like protease (3CL-PRO), the primase complex (Nsp7-Nsp8), the primary RNA-dependent RNA polymerase (Nsp12, RdRp), a helicase (Nsp13, triphosphatase, Hel), a guanine-N7 methyltransferase (Nsp14, exoribonuclease, ExoN), an uridylate-specific endoribonuclease (Nsp15, NendoU) and a hetero-oligomeric complex (Nsp10/Nsp16, N7- and 2' O-ribose methyl transferase complex). ${ }^{24}$ The genomic 3 end encodes as many as 13 orfs which includes four structural proteins such as spike (S), envelop (E), membrane (M) and nucleocapsid $(\mathrm{N})$ along with nine potential accessory factors (Figure 1). ${ }^{25}$

\section{Significant non-Structural Proteins (NSPs) in COVID-19}

\section{Non-structural protein 1}

Nsp1, a membrane-associated host translation inhibitor protein which anchors replication complex to the cellular membranes. Nsp1 forms a complex with $40 \mathrm{~S}$ ribosomal subunit, that degrades host mRNAs by inducing an endonucleolytic cleavage near the $5^{\prime}$ untranslated region and thus inhibits host translation. ${ }^{26}$ SARS-CoV-2 mRNAs are not prone to nsp1-mediated endonucleolytic degradation because of the presence of 5 -end leader sequence. ${ }^{27}$ By suppressing host gene expression, the leader protein promotes efficient expression of viral genes in infected cells and escape from the host immune response. ${ }^{28}$

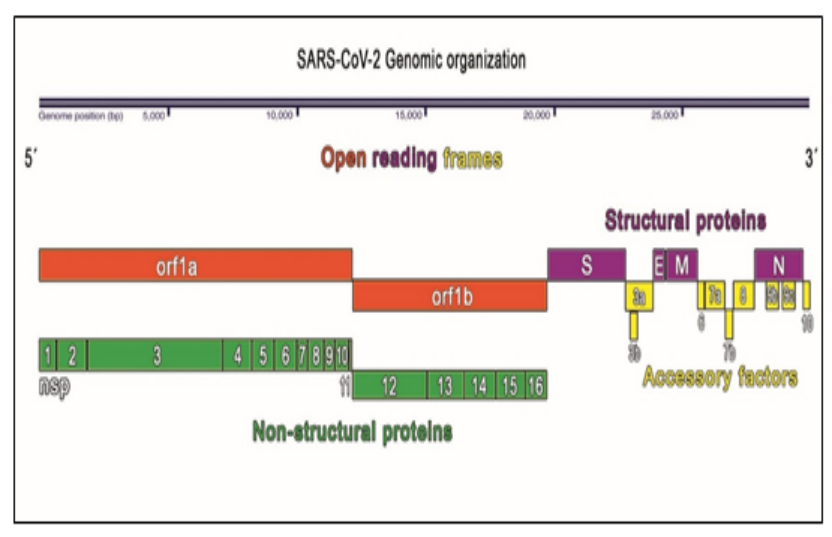

Figure 1: SARS-CoV-2 genomic organization. 


\section{Non-structural protein 2}

Nsp2 plays a vital role in modulation of host cell survival signalling pathway through interaction with host prohibitins (PHB and PHB2). ${ }^{29}$ Prohibitin (B-cell receptor associated protein-32) and prohibitin 2 (repressor of estrogen receptor activity) are ubiquitously expressed and present in several cell compartments like mitochondria, preserving functional integrity and defending cells from various stresses. ${ }^{30}$ The stabilizing mutation occurring inside the endosome-associatedprotein-like domain of the nsp2 protein may account for highly contagious COVID-19. ${ }^{31}$

\section{Non-structural protein 3}

Nsp3, Papain-like protease (PL-PRO) is the largest cystine protease with a proteolytic core domain of 316 amino acids responsible for cleaving first three cleavage sites at the $\mathrm{N}$-terminus of the replicase substrates (poly protiens). ${ }^{32}$ In addition to its role in viral protein maturation, Nsp3 has deubiquitinating/deISGylating activity and processes polyubiquitin chains linked to 'Lys48' and 'Lys63' from cellular substrates to supress antiviral innate immune response of the host cell. ${ }^{33,34}$ Along with Nsp4 and other host proteins, Nsp3 engages in the rearrangement of cytoplasmic double-membrane vesicle required for the replication of SARS-CoV-2. ${ }^{35}$ Nsp3 also prevents host Nuclear Factor Kappa B (NF$x \mathrm{~B})$ signalling and antagonizes innate immune response of type I interferon by blocking phosphorylation, dimerization and subsequent nuclear translocation of host interferon regulatory factor 3 (IRF3). ${ }^{36,37}$ The destabilizing mutation happening near the phosphatase domain of the Nsp3 may suggest a potential mechanism that differentiates SARS-CoV-2 from SARS. Because of its diverse actions, Nsp3 may provide new avenues for investigating the virus replication cycle in host cells, with the goal of developing therapeutic agents to inhibit replication of SARS-CoV-2.

\section{Non-structural protein 4}

Nsp4, a membrane-spanning protein interacts with Nsp3 and other host proteins and plays a significant role in SARS-CoV replication through the rearrangements of viral induced cytoplasmic double-membrane vesicles. ${ }^{38}$ The alpha helical (C-terminal) domain may be involved in protein-protein interactions that anchors the viral replicase-transcriptase complex to modified cytoplasmic membranes necessary for viral replication. ${ }^{39}$

\section{Non-structural protein 5}

Nsp5, chymotrypsin-like protease (3CL-PRO) or Main protease $\left(\mathrm{M}^{\mathrm{pro}}\right)$, a key enzyme responsible for SARS-
CoV-2 replication. ${ }^{40}$ The $\mathrm{M}^{\text {pro }}$ exists in homodimer and has Cys-His dyad on active site which shows protease activity. ${ }^{41} \mathrm{Nsp} 5$ digest replicase polyprotein (C-terminus) at 11 conserved sites to generate non-structural proteins (Nsp4-Nsp16), which plays a vital role in mediating viral replication and transcription and serves as a desirable target for discovery and development of antivirals against COVID-19. ${ }^{42}$

\section{Non-structural protein 6}

SARS-CoV-2 non-structural protein 6 (Nsp6) binds with sigma receptor of host endoplasmic reticulum and

\begin{tabular}{|c|c|c|}
\multicolumn{2}{|c|}{ Table 1: Putative functions of SARS-CoV-2 } \\
non-structural proteins.
\end{tabular}


initiates the induction of autophagosomes. ${ }^{43}$ Generally sigma receptor activation regulates endoplasmic reticulum stress response. Nsp6-sigma receptor interaction restricts autophagosomal expansion, which is no longer capable of delivering viral products to host lysosomes. ${ }^{44} \mathrm{Nsp} 3$, Nsp4 and Nsp6 all together have the capability to induce double-membrane vesicles in which Nsp3 and Nsp4 are capable of pairing membranes while Nsp6 has membrane proliferation ability. ${ }^{45}$

\section{Non-structural protein $7 / 8$ complex}

Nsp7 binds with Nsp8 (8 subunits of each) to form a hexadecamer known as primase complex that interacts with RNA-dependent RNA polymerase (Nsp12) and forms hetero-oligomeric complex (Nsp12-Nsp7/Nsp8) that may participate in SARS-CoV-2 replication. ${ }^{46}$ Moreover, these Nsps can synthesize significantly longer products than oligonucleotide polymers. Nsp8 was predicted to have adhesins, essential for viral adherence and host invasion. ${ }^{47}$

\section{Non-structural protein 9}

Nsp9 acts as a single-stranded RNA-binding protein that mediates both viral replication and virulence. Nsp9, an essential protein binds RNA through oligosaccharide/ oligonucleotide fold-like fold that is unique to the class of $\beta \mathrm{CoVs}$ and promotes viral replication. ${ }^{48} \mathrm{Nsp} 9$ plays a crucial role in SARS-CoV virulence and may play a similar role in upholding functional integrity of SARSCoV-2 due to the $97 \%$ sequence identity. ${ }^{49}$ Researchers have determined the structure of Nsp9 and identified a peptide binding site which could prompt further research in understanding its role in COVID-19. ${ }^{50}$

\section{Non-structural protein 10}

Nsp10, an essential cofactor that activates guanine-N7 methyltransferase (Nsp14) and 2' O-ribose methyltransferase (Nsp16) and plays an important part in methylation of mRNAs guanosine cap to promote transcription, splicing, polyadenylation and nuclear export of viral mRNA. ${ }^{51}$ The hetero-oligomeric complex (Nsp10-Nsp14-Nsp16) may be a target for the development of antivirals against pathogenic coronaviruses. ${ }^{52}$

\section{Non-structural protein 11}

Nsp11, a shortest peptide expressed at the end of orf1a polyprotein of SARS-CoV-2 replicase genome having $85 \%$ amino acid similarity with bat-SL-CoVZXC21 and SARS-CoV. ${ }^{53}$

\section{Non-structural protein 12}

Nsp12, a RNA-dependent RNA polymerase (RdRp), is primarily responsible for replication and transcription of the SARS-CoV-2 genome. ${ }^{54}$ The Nsp12 has ssRNA and ssDNA-dependent polymerase activity with no priming activity and is involved in post transcriptional gene slicing (PTGS). ${ }^{55}$ SARS-CoV-2 nucleotide polymerase was predicted to have 932 amino acids with N-terminal and a polymerase domain. The amino acid sequence alignment showed that SARS-CoV-2 Nsp12 shared $96.35 \%$ similarity to SARS Nsp12. The Nsp12 interacts with Nsp7/Nsp8 complex (Primase complex) and activates to form RNA synthesis machinery to replicate long $\mathrm{RNA}^{56}$ On the other side, the SARSCoV-2 nsp12 possess seven conserved motifs (motifs A-E) in the polymerase active site, which are involved in a template and nucleotide binding and catalysis. ${ }^{57}$ The hetero-oligomeric complex (Nsp12-Nsp7/Nsp8) could be the potential target (PDB ID:6M71) to inhibit the RdRp activity of Nsp12 and helps researchers to identify a novel antiviral agent against SARS-CoV-2. ${ }^{58}$

\section{Non-structural protein 13}

Nsp13, Helicase (Hel) or Nucleoside-triphosphatase (NTPase), a multifunctional protein with a zinc-binding domain in N-terminus unwinds duplex RNA and DNA with a $5^{\prime}$ single-stranded tail in a $5^{\prime}$ to $3^{\prime}$ direction and plays an important role in central dogma of the virus. ${ }^{59}$ Despite its significant role in the replication of SARSCoV-2 RNA, Nsp13 readily unwinds duplex DNA due to its functional cooperativity rather than structural interactions between helicase monomers. ${ }^{60}$ The helicase activity depends on magnesium and may exhibit various properties during unwinding of RNA. ${ }^{61}$ Due to its NTPase and helicase activities, SARS-CoV-2 helicase plays a crucial role in replication and virulence and is considered as a target for antivirals. ${ }^{62}$

\section{Non-structural protein 14}

Nsp14, a bifunctional replicase subunit with exoribonuclease activity (proofreading) that acts in a $3^{\prime}$ to $5^{\prime}$ direction on both ssRNA and dsRNA and a guanine-N7 methyltransferase activity at its C-terminal. ${ }^{63,64}$ The Nsp10 interacts with Nsp14 and Nsp16 in order to form a dodecamer to enhance their enzyme activities and plays a key role in RNA synthesis and replication fidelity. ${ }^{65}$ The N-terminal portion of Nsp14 interacts with ATP-dependent RNA helicase (DDX1) C-terminal region which enhances replication process. ${ }^{66}$ 


\begin{tabular}{|c|c|c|c|}
\hline Nsp & PDB Id & Protein (PDB) & References \\
\hline Nsp3 & $6 \mathrm{~W} 6 \mathrm{Y}$ & $\begin{array}{l}\text { Crystal structure of ADP ribose phosphatase of nsp3 from } \\
\text { SARS-CoV-2 }\end{array}$ & 77 \\
\hline Nsp5 & 6LU7 & $\begin{array}{c}\text { SARS-CoV-2 main protease in complex with an inhibitor } \\
\text { N3 }\end{array}$ & 78 \\
\hline Nsp7/Nsp8 & $6 \mathrm{YHU}$ & Crystal structure of the nsp7-nsp8 complex of SAR-CoV-2 & 79 \\
\hline Nsp9 & $6 W X D$ & SARS-CoV-2 Nsp9 RNA-replicase & 80 \\
\hline Nsp12 & $6 \mathrm{M} 71$ & $\begin{array}{l}\text { SARS-CoV-2 RNA-dependent RNA polymerase in } \\
\text { complex with cofactors }\end{array}$ & 81 \\
\hline Nsp15 & 6W01 & $\begin{array}{l}\text { Crystal structure of nsp15 Endoribonuclease from SARS- } \\
\text { CoV-2 in the complex with a citrate }\end{array}$ & 82 \\
\hline $\begin{array}{l}\text { nsp16-nsp10 } \\
\text { complex }\end{array}$ & $6 \mathrm{~W} 4 \mathrm{H}$ & $\begin{array}{l}\text { Crystal structure of nsp16-nsp10 heterodimer from SARS- } \\
\text { CoV-2 in complex with S-adenosylmethionine }\end{array}$ & 83 \\
\hline
\end{tabular}

\section{Non-structural protein 15}

$\mathrm{Nsp15}$, a $\mathrm{Mn}^{2+}$-dependent nidoviral uridylate-specific endoribonuclease (NendoU) that leaves $2^{\prime}-3^{\prime}$-cyclic phosphatases $5^{\prime}$ to the cleave bond and performs various vital functions associated with RNA processing. ${ }^{67}$ Nsp15 acts as interferon (IFN) antagonist and inhibits interferon- $\beta$ production through an endonuclease activity-independent mechanism. ${ }^{68}$ Moreover, Nsp8 and Nsp7/Nsp8 complex enhances endoribonuclease activity of hexameric Nsp15. ${ }^{69}$

\section{Non-structural protein 16}

Nsp16, 2' O-ribose methyltransferase facilitates methylation of mRNA cap 2' O-ribose to the $5^{\prime}$-cap structure of viral $\mathrm{mRNAs}$ to form N7-methyl guanosine cap and plays an important role in methylation of viral mRNAs cap which is necessary for evading immune system. ${ }^{70,71}$ The enzymatic activity of Nsp16 is increased by interaction with Nsp10 and is essential for viral replication-transcription in host cells. ${ }^{72}$ With the ongoing threat of SARS-CoV-2 virulence, it is important to use the highly conserved Nsp10/Nsp16 heterodimer interface to establish new treatment strategies againstSARS-CoV-2. ${ }^{73}$

Due to the lack of FDA approved drugs for the treatment of human coronavirus infection and vaccines to prevent COVID-19, research against SARS-CoV-2 is ongoing globally. Furthermore, there are many SARSCoV-2 proteins that have been reported as possible targets for drugs. ${ }^{74}$ In addition to the structural proteins, non-structural proteins also play a significant role in the replication and virulence of SARS-CoV-2. Bioinformatic tools can be used to predict drug-like properties, ADMET properties, toxicity profiles, bioactivity scores and antiviral properties for any experimental drug molecule. In silico molecular docking studies can be useful to predict the binding affinity between the experimental drug and the target protein (Table 2) and play a vital role in finding an inhibitor through structurebased drug design. The key limitation of the in-silico studies has false positive results and low coefficients of correlation between the predicted binding energies and experimental values provided in previous research. ${ }^{75}$ Despite the drawbacks, the molecular interactions, dock scores and binding energies provide potential information that can notify and guide further in vitro, in vivo and clinical studies. ${ }^{76}$

\section{CONCLUSION}

The ongoing COVID-19 pandemic clearly reflects a global public health issue. The novel coronavirus, SARS$\mathrm{CoV}-2$ spreads rapidly due to its pre- and asymptomatic silent transmission. The review summarized multiple pathologic functions of non-structural proteins in SARS-CoV-2 replication and virulence. Several Nsps assembled to form replicase-transcriptase and heterooligomeric complexes and exhibit multiple enzymatic activity. Moreover, there is urgent need to identify and characterize potent antiviral compound against specific targets (Nsps) to combat the emerging COVID-19 pandemic. Our review might contribute by providing substantial information regarding the role of SARSCoV-2 non-structural proteins in COVID-19. 


\section{ACKNOWLEDGEMENT}

The authors are grateful to the management, College of Pharmacy, Koneru Lakshmaiah Education Foundation, Vaddeswaram, A.P., India.

\section{CONFLICT OF INTEREST}

No conflict of interest declared by the authors.

\section{ABBREVIATIONS}

CoV: Coronavirus; SARS-CoV-2: Severe acute respiratory syndrome coronavirus 2 ; orfs: Open reading frames; COVID-19: Coronavirus disease 2019; $\beta$ CoVs: Beta coronavirus; mRNA: Messenger ribonucleic acid; WHO: World health organization; Nsps: Nonstructural proteins; PL-PRO: Papain-like protease; $\mathbf{M}^{\text {pro: }}$ Main protease; 3CL-PRO: Chymotrypsin-like protease; NendoU: $\quad$ Uridylate-specific endoribonuclease; RdRp: RNA-dependent RNA polymerase; ExoN: Exoribonuclease; Hel: Helicase; S: Spike; E: Envelop; M: Membrane; N: Nucleocapsid; PHB: prohibitin; NF- $\boldsymbol{\varkappa B}$ : Nuclear factor kappa B; PDB: Protein data bank; DNA: Deoxyribonucleic acid; IFN: Interferon; IRF3: Interferon regulatory factor 3 .

\section{REFERENCES}

1. Wu F, Zhao S, Yu B, Chen YM, Wang W, Song ZG, et al. A new coronavirus associated with human respiratory disease in China. Nature. 2020;579(7798):265-9. doi: https://doi.org/10.1038/s41586-020-2008-3.

2. Dhama K, Sharun K, Tiwari R, Dadar M, Malik YS, Singh KP, et al. COVID-19, an emerging coronavirus infection: advances and prospects in designing and developing vaccines, immunotherapeutics and therapeutics. Hum Vaccines Immunother. 2020;16:1-7. doi: https://doi.org/10.1080/21645515.2020.1735 227.

3. Baldwin R, DiMauro BW. Economics in the Time of COVID-19, a VoxEU.org eBook. CEPR Press. 2020

4. Cascella M, Rajnik M, Cuomo A, Dulebohn SC, DiNapoli R. Features, evaluation and treatment coronavirus (COVID-19). In: Stat Pearls Publishing. Treasure Island (FL). 2020. Available form: https://www.ncbi.nlm.nih.gov/ books/NBK554776/.

5. Coronaviridae study group of the international committee on taxonomy of viruses. The species severe acute respiratory syndrome-related coronavirus: Classifying 2019-nCoV and naming it SARS-CoV-2. Nat Microbiol. 2020;5(4):536-44.

6. Li LQ, Huang T, Wang YQ, Wang ZP, Liang Y, Huang TB, et al. 2019 novel coronavirus patients' clinical characteristics, discharge rate and fatality rate of meta-analysis. J Med Virol. 2020;1-7. doi: https://doi.org/10.1002/jmv.25757.

7. Wujtewicz M, Dylczyk-Sommer A, AszkiełowiczA, Zdanowski S, Piwowarczyk S, Owczuk R. COVID-19-what should anaethesiologists and intensivists know about it?. Anaesthesiol Intensive Ther. 2020;52(1):34-41. doi: https:// doi.org/10.5114/ait.2020.93756.

8. Moghadas SM, Fitzpatrick MC, Sah P, Pandey A, Shoukat A, Singer BH, et al. The implications of silent transmission for the control of COVID-19 outbreaks. Proc Natl Acad Sci. 2020;117(30):17513-5. https://doi.org/10.1073/ pnas.2008373117.

9. Le TQ, Takemura T, Moi ML, Nabeshima T, Nguyen LK, Hoang VM, et al. Severe acute respiratory syndrome coronavirus 2 shedding by travelers,
Vietnam, 2020. Emerg Infect Dis. 2020;26(7):1624-6. https://dx.doi. org/10.3201/eid2607.200591.

10. He X, Lau EH, Wu P, Deng X, Wang J, Hao X, et al. Temporal dynamics in viral shedding and transmissibility of COVID-19. Nat Med. 2020;26(5):6725. https://doi.org/10.1038/s41591-020-0869-5.

11. Zhang $\mathrm{H}$, Kang Z, Gong $\mathrm{H}, \mathrm{Xu} \mathrm{D}$, Wang J, Li Z, et al. Digestive system is a potential route of COVID-19: An analysis of single-cell coexpression pattern of key proteins in viral entry process. Gut. 2020;69(6):1010-8. http://dx.doi. org/10.1136/gutjnl-2020-320953.

12. Zu ZY, Jiang MD, Xu PP, Chen W, Ni QQ, Lu GM, et al. Coronavirus disease 2019 (COVID-19): A perspective from China. Radiology. 2020;21:200490. doi: https://doi.org/10.1148/radiol.2020200490.

13. Hassan S, Sheikh FN, Jamal S, Ezeh JK, Akhtar A. Coronavirus (COVID-19): A Review of Clinical Features, Diagnosis and Treatment. Cureus. 2020;12(3):e7355. doi: https://doi.org/10.7759/cureus.7355.

14. Wang $Y$, Wang $Y$, Chen $Y$, Qin Q. Unique epidemiological and clinical features of the emerging 2019 novel coronavirus pneumonia (COVID-19) implicate special control measures. J Med Virol. 2020;92(6):568-76. Available form: https://onlinelibrary.wiley.com/doi/full/10.1002/jmv.25748.

15. Chen N, Zhou M, Dong X, Qu J, Gong F, Han Y, et al. Epidemiological and clinical characteristics of 99 cases of 2019 novel coronavirus pneumonia in Wuhan, China: A descriptive study. Lancet. 2020;395(10223):507-13. https:// doi.org/10.1053/j.gastro.2020.03.065.

16. Pathak N. The great invader: How COVID attacks every organ. 2020. Available from: URL: https://www.webmd.com/lung/news/20200423/thegreat-invader-how-covid-attacks-every-organ.

17. Li D, Jin M, Bao P, Zhao W, Zhang S. Clinical characteristics and results of semen tests among men with coronavirus disease 2019. JAMA Netw. 2020;3(5):e208292.

18. Moghadas SM, Fitzpatrick MC, Sah P, Pandey A, Shoukat A, Singer BH, et al. The implications of silent transmission for the control of COVID-19 outbreaks. Proc Natl Acad Sci. 2020;202008373. https://doi.org/10.1073/ pnas.2008373117.

19. Jaimes JA, Andre NM, Chappie JS, Millet JK, Whittaker GR. Phylogenetic analysis and structural modelling of SARS-CoV-2 spike protein reveals an evolutionary distinct and proteolytically-sensitive activation loop. J Mol Biol. 2020;432(10):3309-25. https://doi.org/10.1016/j.jmb.2020.04.009.

20. Gordon DE, Jang GM, Bouhaddou M, Xu J, Obernier K, O'meara MJ, et al. A SARS-CoV-2-Human Protein-Protein Interaction Map Reveals Drug Targets and Potential Drug-Repurposing. Bio Rxiv. 2020. Available from: URL: https:// www.biorxiv.org/content/10.1101/2020.03.22.002386v3.

21. Lu R, Zhao X, Li J, Niu P, Yang B, Wu H, et al. Genomic characterisation and epidemiology of 2019 novel coronavirus: Implications for virus origins and receptor binding. Lancet. 2020;395(10224):565-74. doi: https://doi. org/10.1016/S0140-6736(20)30251-8.

22. Cui J, Li F, Shi ZL. Origin and evolution of pathogenic coronaviruses. Nat Rev Microbiol. 2019;17(3):181-92. doi: https://doi.org/10.1038/s41579-0180118-9.

23. Báez-Santos YM, John SE, Mesecar AD. The SARS-coronavirus papain-like protease: structure, function and inhibition by designed antiviral compounds. Antiviral Res. 2015;115:21-38. doi: https://dx.doi.org/10.1016\%2Fj. antiviral.2014.12.015.

24. Graham RL, Sparks JS, Eckerle LD, Sims AC, Denison MR. SARS coronavirus replicase proteins in pathogenesis. Virus Res. 2008;133(1):88100. doi: https://doi.org/10.1016/j.virusres.2007.02.017.

25. Tan YJ, Teng E, Shen S, Tan TH, Goh PY, Fielding BC, et al. A novel severe acute respiratory syndrome coronavirus protein, $U 274$, is transported to the cell surface and undergoes endocytosis. J Virol. 2004;78(13):6723-34. doi: https://doi.org/10.1128/JVI.78.13.6723-6734.2004.

26. Lokugamage KG, Narayanan K, Huang C, Makino S. Severe acute respiratory syndrome coronavirus protein nsp1 is a novel eukaryotic translation inhibitor that represses multiple steps of translation initiation. J Virol. 2012;86(24):13598-608. doi: https://doi.org/10.1128/JVI.01958-12.

27. Dong S, Sun J, Mao Z, Wang L, Lu YL, Li J. A guideline for homology modeling of the proteins from newly discovered betacoronavirus, 2019 novel coronavirus (2019-nCoV). J Med Virol. 2020;2020:1-7. doi: https://doi. org/10.1002/jmv.25768. 
28. Gottipati K, Woodson M, Choi KH. Membrane binding and rearrangement by chikungunya virus capping enzyme nsP1. Virol. 2020;544:31-41. doi: https:// doi.org/10.1016/j.virol.2020.02.006.

29. Angeletti S, Benvenuto D, Bianchi M, Giovanetti M, Pascarella S, Ciccozzi M. COVID-2019: The role of the nsp2 and nsp3 in its pathogenesis. J Med Virol. 2020;2020:1-5. doi: https://doi.org/10.1002/jmv.25719.

30. Chowdhury I, Thompson WE, Thomas K. Prohibitins role in cellular survival through Ras-Raf-MEK-ERK pathway. J Cell Physiol. 2014;229(8):998-1004. doi: https://doi.org/10.1002/jcp.24531.

31. Guo YR, Cao QD, Hong ZS, Tan YY, Chen SD, Jin HJ, et al. The origin, transmission and clinical therapies on coronavirus disease 2019 (COVID-19) outbreak-an update on the status. Mil Med Res. 2020;7(1):1-0. doi: https:// doi.org/10.1186/s40779-020-00240-0.

32. Barretto N, Jukneliene D, Ratia K, Chen Z, Mesecar AD, Baker SC. The papain-like protease of severe acute respiratory syndrome coronavirus has deubiquitinating activity. J Virol. 2005;79(24):15189-98. doi: https://doi. org/10.1128/JVI.79.24.15189-15198.2005.

33. Lei J, Hilgenfeld R. Structural and mutational analysis of the interaction between the Middle-East respiratory syndrome coronavirus (MERS-CoV) papain-like protease and human ubiquitin. Virol Sin. 2016;31(4):288-99. doi: https://doi.org/10.1007/s12250-016-3742-4.

34. Clasman JR, Everett RK, Srinivasan K, Mesecar AD. Decoupling delSGylating and deubiquitinating activities of the MERS virus papain-like protease. Antivir Res. 2020;174:104661. doi: https://doi.org/10.1016/j.antiviral.2019.104661.

35. Sakai Y, Kawachi K, Terada Y, Omori H, Matsuura Y, Kamitani W. Two-amino acids change in the nsp4 of SARS coronavirus abolishes viral replication. Virol. 2017;510:165-74. doi: https://doi.org/10.1016/j.virol.2017.07.019.

36. Santoro MG, Rossi A, Amici C. NF-KB and virus infection: Who controls whom. EMBO J. 2003;22(11):2552-60. doi: https://doi.org/10.1093/emboj/ cdg267.

37. Chiang HS, Liu HM. The Molecular Basis of Viral Inhibition of IRF-and STATDependent Immune Responses. Front Immunol. 2019;9:3086. doi: https:// doi.org/10.3389/fimmu.2018.03086.

38. Fung TS, Liu DX. Coronavirus infection, ER stress, apoptosis and innate immunity. Front Microbiol. 2014;5:296. doi: https://doi.org/10.3389/ fmicb.2014.00296.

39. Manolaridis I, Wojdyla JA, Panjikar S, Snijder EJ, Gorbalenya AE, Berglind $\mathrm{H}$, et al. Structure of the C-terminal domain of nsp4 from feline coronavirus. Acta Crystallogr Sect D: Biol Crystallogr. 2009;65(8):839-46. doi: https://doi. org/10.1107/S0907444909018253.

40. Yang H, Xie W, Xue X, Yang K, Ma J, Liang W, et al. Design of wide-spectrum inhibitors targeting coronavirus main proteases. PLoS Biol. 2005;3(10):e324. doi: https://doi.org/10.1371/journal.pbio.0030324.

41. Shimamoto $Y$, Hattori $Y$, Kobayashi K, Teruya K, Sanjoh A, Nakagawa A, et al. Fused-ring structure of decahydroisoquinolin as a novel scaffold for SARS 3CL protease inhibitors. Bioorgan Med Chem. 2015;23(4):876-90. doi: https://doi.org/10.1016/j.bmc.2014.12.028.

42. Wu C, Liu Y, Yang Y, Zhang P, Zhong W, Wang Y, et al. Analysis of therapeutic targets for SARS-CoV-2 and discovery of potential drugs by computational methods. Acta Pharm Sin B. 2020;2020:1-44. doi: https://doi.org/10.1016/j. apsb.2020.02.008.

43. Mitsuda T, Omi T, Tanimukai H, Sakagami $\mathrm{Y}$, Tagami S, Okochi M, et al. Sigma-1Rs are upregulated via PERK/elF2 $\alpha /$ ATF4 pathway and execute protective function in ER stress. Biochem Bioph Res Co. 2011;415(3):51925. doi: https://doi.org/10.1016/j.bbrc.2011.10.113.

44. Oostra M, Hagemeijer MC, Gent MV, Bekker CP, Lintelo EG, Rottier PJ, et al. Topology and membrane anchoring of the coronavirus replication complex: not all hydrophobic domains of nsp3 and nsp6 are membrane spanning. J Virol. 2008;82(24):12392-405. doi: https://doi.org/10.1128/JVI.01219-08.

45. Angelini MM, Akhlaghpour M, Neuman BW, Buchmeier MJ. Severe acute respiratory syndrome coronavirus non-structural proteins 3,4 and 6 induce double-membrane vesicles. MBio. 2013;4(4):e00524-13. doi: https://doi. org/10.1128/mBio.00524-13.

46. Krichel B, Falke S, Hilgenfeld R, Redecke L, Uetrecht C. Processing of the SARS-CoV pp1a/ab nsp7-10 region. Biochem J. 2020;477(5):1009-19. doi: https://doi.org/10.1101/860049.

47. Tevelthuis AJ, Worm SHV, Snijder EJ. The SARS-coronavirus nsp7+ nsp8 complex is a unique multimeric RNA polymerase capable of both de novo initiation and primer extension. Nucleic acids Res. 2012;40(4):1737-47. doi: https://doi.org/10.1093/nar/gkr893.

48. Miknis ZJ, Donaldson EF, Umland TC, Rimmer RA, Baric RS, Schultz LW. Severe acute respiratory syndrome coronavirus nsp9 dimerization is essential for efficient viral growth. J Virol. 2009;83(7):3007-18. doi: https:// doi.org/10.1128/JVI.01505-08.

49. Littler D, Gully B, Colson RN, Rossjohn J. Crystal structure of the SARSCoV-2 non-structural protein 9, Nsp9. Bio Rxiv. 2020. Available from: URL: https://www.biorxiv.org/content/10.1101/2020.03.28.013920v1.

50. Tan K, Kim Y, Jedrzejczak R, Maltseva N, Endres M, Michalska K, et al. Center for Structural Genomics of Infectious Diseases (CSGID) The crystal structure of Nsp9 RNA binding protein of SARS CoV-2 from E. coli. 2020. doi: https://doi.org/10.2210/pdb6W4B/pdb.

51. Ong E, Wong MU, Huffman A, He Y. COVID-19 coronavirus vaccine design using reverse vaccinology and machine learning. Bio Rxiv. 2020. Available from: URL: https://www.biorxiv.org/content/10.1101/2020.03.20.000141v1.

52. Bouvet M, Lugari A, Posthuma CC, Zevenhoven JC, Bernard S, Betzi S, et al. Coronavirus Nsp10, a critical co-factor for activation of multiple replicative enzymes. J Biol Chem. 2014;289(37):25783-96.

53. Fang SG, Shen H, Wang J, Tay FP, Liu DX. Proteolytic processing of polyproteins 1a and $1 \mathrm{ab}$ between non-structural proteins 10 and 11/12 of Coronavirus infectious bronchitis virus is dispensable for viral replication in cultured cells. Virol. 2008;379(2):175-80. doi: https://doi.org/10.1016/j. virol.2008.06.038.

54. Kirchdoerfer RN, Ward AB. Structure of the SARS-CoV nsp12 polymerase bound to nsp7 and nsp8 co-factors. Nat Commun. 2019;10(1):1-9. doi: https://doi.org/10.1038/s41467-019-10280-3.

55. Wu J, Gong P. Visualizing the nucleotide addition cycle of viral RNAdependent RNA polymerase. Viruses. 2018;10(1):24. doi:https://doi. org/10.3390/v10010024.

56. Subissi L, Posthuma CC, Collet A, Zevenhoven-Dobbe JC, Gorbalenya $A E$, Decroly $E$, et al. One severe acute respiratory syndrome coronavirus protein complex integrates processive RNA polymerase and exonuclease activities. P Natl A Sci. 2014;111(37):E3900-9. doi: https://doi.org/10.1073/ pnas. 1323705111.

57. Mirza MU, Froeyen M. Structural elucidation of SARS-CoV-2 vital proteins: computational methods reveal potential drug candidates against Main protease, Nsp12 RNA-dependent RNA polymerase and Nsp13 helicase. Preprints. 2020;2020030085. doi: https://doi.org/10.20944/ preprints202003.0085.v1.

58. Gao Y, Yan L, Huang Y, Liu F, Cao L Wang T, et al. Chinese Academy of Sciences; National Natural Science Foundation of China (NSFC). Ministry of Science and Technology (MoST, China) 2019-nCoV RNA-dependent RNA polymerase in complex with cofactors from E. coli BL21(DE3). 2020. doi: https://doi.org/10.2210/pdb6M71/pdb.

59. Zaher NH, Mostafa MI, Altaher AY. Design, synthesis and molecular docking of novel triazole derivatives as potential $\mathrm{CoV}$ helicase inhibitors. Acta Pharmaceut. 2020;70(2):145-59. doi: https://doi.org/10.2478/acph-20200024.

60. Lee NR, Kwon HM, Park K, Oh S, Jeong YJ, Kim DE. Cooperative translocation enhances the unwinding of duplex DNA by SARS coronavirus helicase nsP13. Nucleic Acids Res. 2010;38(21):7626-36. doi: https://doi. org/10.1093/nar/gkq647.

61. Jang KJ, Jeong S, Kang DY, Sp N, Yang YM, Kim DE. A high ATP concentration enhances the cooperative translocation of the SARS coronavirus helicase nsP13 in the unwinding of duplex RNA. Sci Rep. 2020;10(1):1-3. doi: https:// doi.org/10.1038/s41598-020-61432-1.

62. Shu T, Huang M, DiWu YR, Zhang X, Han Y, Mu J, et al. SARS-Coronavirus-2 Nsp 13 possesses NTPase and RNA helicase activities that can be inhibited by bismuth salts. Virol Sin. 2020;35(3):321-9. https://doi.org/10.1007/ s12250-020-00242-1.

63. Fung SY, Yuen KS, Ye ZW, Chan CP, Jin DY. A tug-of-war between severe acute respiratory syndrome coronavirus 2 and host antiviral defence: Lessons from other pathogenic viruses. Emerg Microbes Infect. 2020;9(1):558-70. doi: https://doi.org/10.1080/22221751.2020.1736644.

64. Ogando N, Ferron F, Decroly E, Bruno C, Posthuma C, Snijder E. The curious case of the nidovirus exoribonuclease: Its role in RNA synthesis and 
replication fidelity. Front Microbiol. 2019;10:1813. doi: https://doi.org/10.3389/ fmicb.2019.01813.

65. Bouvet M, Imbert I, Subissi L, Gluais L, Canard B, Decroly E. RNA 3'-end mismatch excision by the severe acute respiratory syndrome coronavirus nonstructural protein nsp10/nsp14 exoribonuclease complex. Proc Natl Acad Sci. 2012;109(24):9372-7. doi: https://doi.org/10.1073/pnas.1201130109.

66. Xu L, Khadijah S, Fang S, Wang L, Tay FP, Liu DX. The cellular RNA helicase DDX1 interacts with coronavirus non-structural protein 14 and enhances viral replication. J Virol. 2010;84(17):8571-83. doi: https://doi.org/10.1128/ JVI.00392-10.

67. Senanayake SL. Overcoming nonstructural protein 15-nidoviral uridylatespecific endoribonuclease (nsp15/NendoU) activity of SARS-CoV-2. Future Drug Discov. 2020;2(3):FDD42. doi: https://doi.org/10.4155/fdd-2020-0012.

68. Hu Y, Li W, Gao T, Cui Y, Jin Y, Li P, et al. The severe acute respiratory syndrome coronavirus nucleocapsid inhibits type I interferon production by interfering with TRIM25-mediated RIG-I ubiquitination. J Virol. 2017;91(8):e02143-16. doi: https://doi.org/10.1128/JVI.02143-16.

69. Zhang L, Li L, Yan L, Ming Z, Jia Z, Lou Z, et al. Structural and biochemical characterization of endoribonuclease Nsp15 encoded by Middle East respiratory syndrome coronavirus. J Virol. 2018;92(22):e00893-18. doi: https://doi.org/10.1128/JVI.00893-18.

70. Wang Y, Sun Y, Wu A, Xu S, Pan R, Zeng C, et al. Coronavirus nsp10/nsp16 methyltransferase can be targeted by nsp10-derived peptide in vitro and in vivo to reduce replication and pathogenesis. J Virol. 2015;89(16):8416-27. doi: https://doi.org/10.1128/JVI.00948-15.

71. Menachery VD, Debbink K, Baric RS. Coronavirus non-structural protein 16: Evasion, attenuation and possible treatments. Vir Res. 2014;194:191-9. doi: https://doi.org/10.1016/j.virusres.2014.09.009.

72. Chen Y, Su C, Ke M, Jin X, Xu L, Zhang Z, et al. Biochemical and structural insights into the mechanisms of SARS coronavirus RNAribose 2'-O-methylation by nsp16/nsp10 protein complex. PLoS Pathog. 2011;7(10):e1002294. doi: https://dx.doi.org/10.1371\%2Fjournal.ppat.1002294.
73. Monica RL, George M, Ludmilla S, Nicole LI, Olga K, Grant W, et al. The crystal structure of nsp10-nsp16 heterodimer from SARS-CoV-2 in complex with S-adenosylmethionine. Bio Rxiv. 2020.04.17.047498. doi: https://doi. org/10.1101/2020.04.17.047498.

74. Prajapat M, Sarma P, Shekhar N, Avti P, Sinha S, Kaur H, et al. Drug targets for corona virus: A systematic review. Indian J Pharmacol. 2020;52(1):56-65.

75. Wang Z, Sun H, Yao X, Li D, Xu L, Li Y, et al. Comprehensive evaluation of ten docking programs on a diverse set of protein-ligand complexes: the prediction accuracy of sampling power and scoring power. Phys Chem Chem Phys. 2016;18(18):12964-75.

76. Li J, Fu A, Zhang L. An overview of scoring functions used for protein-ligand interactions in molecular docking. Interdiscip Sci. 2019;11(2):320-8.

77. Michalska K, Kim Y, Jedrzejczak R, Maltseva NI, Stols L, Endres M, et al. Crystal structures of SARS-CoV-2 ADP-ribose phosphatase (ADRP): From the apo form to ligand complexes. Bio Rxiv. 2020.05.14.096081. https://doi. org/10.1101/2020.05.14.096081.

78. Jin Z, Du X, Xu Y, Deng Y, Liu M, Zhao Y, et al. Structure of M pro from SARSCoV-2 and discovery of its inhibitors. Nature. 2020;582:289-93.

79. Konkolova E, Klima M, Nencka R, Boura E. Structural analysis of the putative SARS-CoV-2 primase complex. J Struct. 2020;211(2):107548. doi: https:// dx.doi.org/10.1101/2020.04.17.047498.

80. Littler DR, Gully BS, Colson RN, Rossjohn J. Crystal structure of the SARSCoV-2 non-structural protein 9, Nsp9. Iscience. 2020;23(7):101258. https:// doi.org/10.1016/j.isci.2020.101258.

81. Gao Y, Yan L, Huang Y, Liu F, Zhao Y, Cao L, et al. Structure of the RNA-dependent RNA polymerase from COVID-19 virus. Science. 2020;368(6492):779-82.

82. Kim Y, Jedrzejczak R, Maltseva NI, Wilamowski M, Endres M, Godzik A, et al. Crystal structure of nsp15 endoribonuclease NendoU from SARS-CoV-2. Protein Sci. 2020;29(7):1596-605.

83. Rosas-Lemus M, Minasov G, Shuvalova L, Inniss NL, Kiryukhina O, Wiersum G, et al. The crystal structure of nsp10-nsp16 heterodimer from SARS-CoV-2 in complex with S-adenosylmethionine. Bio Rxiv. 2020;32511376.

\section{PICTORIAL ABSTRACT}

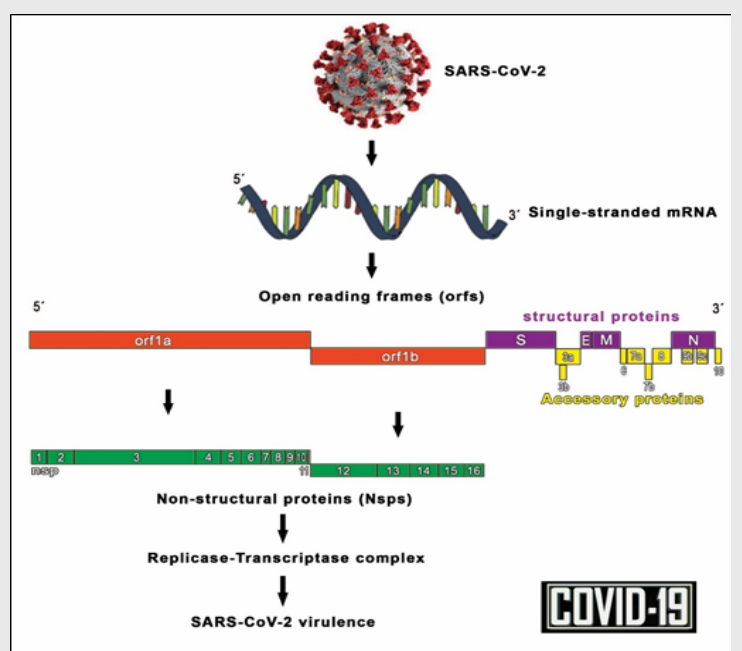

\section{SUMMARY}

- COVID-19, a pandemic respiratory disease associated with high morbidity and mortality worldwide.

- Coronavirus disease 2019 is caused by a novel coronavirus named as "SARS-CoV-2".

- The SARS-CoV-2 genome encodes as many as 14 open reading frames including orf $1 \mathrm{a}$, orf1b, 4 structural proteins and 9 accessory proteins.

- The polyproteins pp1a and pp1b translated from open reading frames (orf1a and orf1b) are preprocessed and fragmented in to 16 nonstructural proteins.

- Several Nsps assembled to form replicasetranscriptase and hetero-oligomeric complexes and plays a significant part in viral replication and virulence.

- Nsps could be appropriate therapeutic targets for investigating replication and pathogenesis of SARS-CoV-2. 


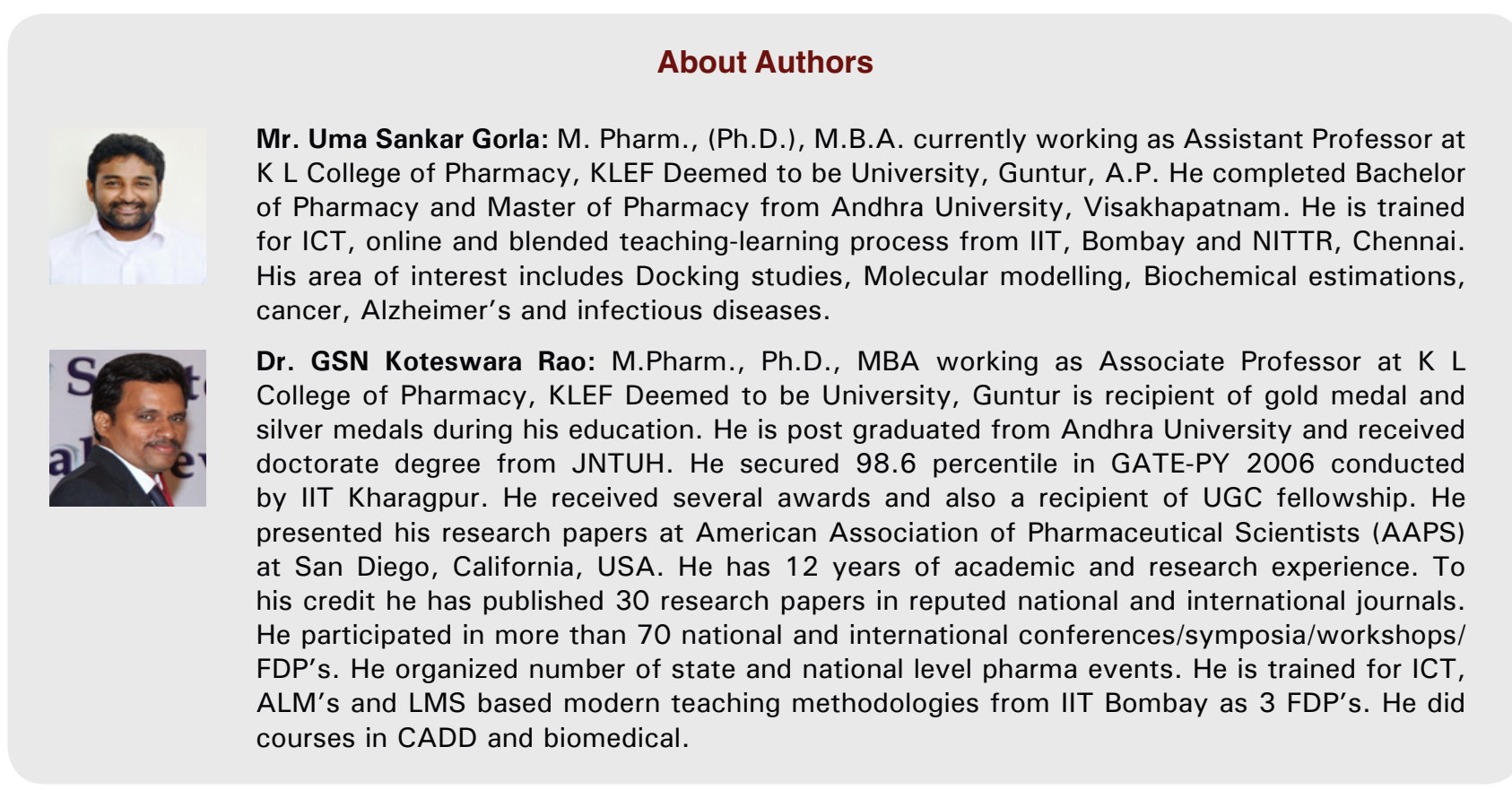

Cite this article: Gorla US, Rao GSNK. SARS-CoV-2: The Prominent Role of Non-structural Proteins (Nsps) in COVID-19. Indian J of Pharmaceutical Education and Research. 2020;54(3s):s381-s389. 